\title{
Testosterone and cortisol patterns and the effects of electro-ejaculation and copulation in Awassi rams
}

\author{
Mazen Alomar, Ahmad Soukouti, Mohee Alden Alzoabi, and Moutaz Zarkawi \\ Division of Animal Production, Department of Agriculture, Atomic Energy Commission, \\ P.O. Box 6091, Damascus, Syria \\ Correspondence to: Mazen Alomar (scientific@aec.org.sy)
}

Received: 9 November 2015 - Revised: 8 February 2016 - Accepted: 19 February 2016 - Published: 14 March 2016

\begin{abstract}
The effects of month, electro-ejaculation (EE) and copulation process on testosterone and cortisol levels were investigated in Syrian Awassi rams. Jugular blood samples were collected from 10 rams at weekly intervals for 1 year. During the breeding and non-breeding season, samples were collected 60 min before EE and copulation as well as 0 (at the time of ejaculation), 20 and $60 \mathrm{~min}$ after EE and copulation. Low testosterone levels were detected from October to February $\left(4.58-5.06 \mathrm{nmol} \mathrm{L}^{-1}\right)$, while high levels were noted from May to September $\left(8.01-11.40 \mathrm{nmol} \mathrm{L}^{-1}\right)$ with significant differences among months $(P<0.001)$. In contrast, cortisol levels were low from March to October $\left(0.63-2.27 \mathrm{nmol} \mathrm{L}^{-1}\right)$ and the highest level was recorded in December $\left(11.30 \mathrm{nmol} \mathrm{L}^{-1}\right)$ with a significant month effect $(P<0.001)$. Cortisol reached its maximum concentration in the electrically stimulated rams 20 min post electro-ejaculation with no significant difference between the two seasons at this end time point. Means of testosterone levels differed between the breeding and the non-breeding season for electro-ejaculated rams. An increase in testosterone level was observed after 60 min of copulation process in the non-breeding, while no differences were noted for this hormone over the four time periods during the breeding season. Cortisol levels rose significantly in non-breeding season at 0 and 20 min after copulation $(P<0.001)$. In conclusion, Syrian Awassi rams displayed a clear seasonality of testosterone and cortisol. Cortisol levels indicate an acute stress response to EE treatment. Females have an effect on testosterone and cortisol levels in Syrian Awassi rams only during the non-breeding season.
\end{abstract}

\section{Introduction}

It is well known that sheep species have marked seasonality of their breeding activity (Rosa and Bryant, 2003). Reproductive seasonality in the ewe was characterized by changes at behavioural, endocrine and ovulatory levels (Avdi et al., 1993). However, in the ram, testicular size and efficiency of spermatogenesis have differed between breeding and non-breeding season (Kafi et al., 2004). Moreover, seasonal changes in testosterone concentrations during a 1-year period have been used to determine that breeds such as Chios and Daglic are seasonal breeders (Gundogan, 2007). Testosterone secretion in small ruminants was driven by natural day length changes or artificial photoperiodic cycles (Langford et al., 1999). In addition to photoperiod effect, copulation process altered the levels of testosterone in males in a number of species such as humans, cattle and rats (Katongole et al.,
1971; Fox et al., 1972; Purvis and Haynes, 1974). Nevertheless, such alteration was not always obvious in rams during the breeding and non-breeding season (Purvis et al., 1974; Gonzalez et al., 1988a, b, 1991).

Semen collection is an essential step to achieve artificial insemination (AI) and other reproductive techniques. In most domestic livestock species, the collection of semen could be conducted throughout the year during breeding and non-breeding season. However, semen can be collected from live animals by using artificial vaginas, but this technique requires a previous training period for males (WulsterRadcliffe et al., 2001). Electro-ejaculation (EE) is an alternative technique when males are not trained to artificial vaginas. This method allowed the collection of high-quality semen from bulls and rams (Palmer, 2005; Garcia-Alvarez et al., 2009) without noticeable differences from those col- 
lected by artificial vaginas. Electro-ejaculation without anesthesia in humans and animals is known to be painful; elevated blood pressure and cortisol levels have been reported (Ortiz de Montellano et al., 2007; Damian and Ungerfeld, 2011). In this respect, cortisol is often used in stress and welfare assessments (Kannan et al., 2002), and it measures acute pain (Mosure et al., 1998). It is worth noting that the values and the relation between cortisol and testosterone secretion after exposure to stressful stimuli and copulation process were not always clear in sheep species.

Awassi is the predominant sheep breed in Syria and the Middle East (Galal et al., 2008). This breed is well adapted to harsh environmental conditions and raised primarily for three types of products: meat, milk and wool (Iniguez and Hilali, 2009). Although seasonality pattern of Awassi rams has been previously reported (Taha et al., 2000; Kridli et al., 2007), little information is available about the seasonal profile of both testosterone and cortisol and the effects of electro-ejaculation and copulation process on Awassi rams. Therefore, the objectives of the current experiments were (1) to determine the seasonal pattern of testosterone and cortisol in Syrian Awassi rams during a period of 1 year and (2) to investigate electro-ejaculation and copulation effects on cortisol and testosterone levels during the breeding and non-breeding season.

\section{Materials and methods}

\subsection{Site description}

The present study was carried out at the Division of Animal Production, Der Al-Hajar Research Centre, located at $33^{\circ} 21^{\prime} \mathrm{N}, 36^{\circ} 28^{\prime} \mathrm{E}$ and $617 \mathrm{~m}$ above sea level. This area is dry with an annual rainfall of about $140 \mathrm{~mm}$. The climatological data of this study were collected from a climatological station inside the centre. The average longest and lowest day length was in June (14 h $22 \mathrm{~min}$ ) and January (10 h $14 \mathrm{~min})$, respectively. For temperature, the average maximum day temperature was recorded in August $\left(40.77^{\circ} \mathrm{C}\right)$ while the minimum day temperature was recorded in January $\left(14.50^{\circ} \mathrm{C}\right)$.

\subsection{Animals}

At the start of the study, 10 sexually experienced Syrian Awassi rams aged between 2 and 4 years (weighing mean $\pm \mathrm{SD} ; 90 \pm 8.8 \mathrm{~kg}$ ) were used. Rams were maintained in an open-side barn, exposed to natural photoperiod and isolated from any other animals. The 10 rams were fed a diet based on concentrate and wheat straw, while water was available ad libitum.

\subsection{Experiments}

Three experiments were conducted in this study; for all experiments, blood samples were collected from the jugular vein using heparinized evacuated tubes with minimal disturbance and immediately centrifuged at $2000 \times g$ for $15 \mathrm{~min}$. Plasma was prepared and stored at $-20^{\circ} \mathrm{C}$ until the hormones assayed.

In the first experiment, a weekly collection of blood was done under the same conditions at 09:00 LT (NovemberMarch: UTC +2 , April-October: UTC +3 ), and this experiment lasted for 1 year.

In the second experiment, electrical stimulation was applied with the aid of an electro-ejaculator (ElectroJac 5, Ideal Instruments, USA) administrating a series of 32-cycle pulses of short electrical stimuli with each cycle ( $2 \mathrm{~s}$ on, then $2 \mathrm{~s}$ off) delivering a slightly higher intensity until semen production. The entire procedure was performed in approximately $2 \mathrm{~min}$ and repeated directly if the ram did not respond. The rams were not previously subjected to electro-ejaculation process before the conduction of this experiment. Animals were held in a standing position during treatments. In this position, the penis of the rams was easily grasped and held into the end of calibrated centrifuge tube. It must be noted that all used animals were under veterinary care supervision after semen collection, and animal's welfare was highly respected. Blood samples were collected at $60 \mathrm{~min}$ before electrical stimulation as well as 0 (immediately at the time of ejaculation), 20 and $60 \mathrm{~min}$ after electrical stimulation. This experiment was replicated three times in July using the 10 rams (which is normally considered as a part of the breeding season in Awassi sheep according to previous results from our research group), and three times using the same rams in February (which is also considered as a part of the non-breeding season).

In the third experiment, nine Syrian Awassi ewes were synchronized to exhibit oestrus, on three different dates (three ewes on each date) on a weekly interval. Vaginal progestagen sponges ( $40 \mathrm{mg}$ flourogestone acetate, FGA) were inserted for 14 days. The three ewes to be used in the coupling procedures were detected to be in oestrus by experienced Syrian Awassi rams $50 \mathrm{~h}$ after sponge withdrawal. Each ram was individually entered to the females and evaluated by exposing it to two or three oestrus ewes for $15 \mathrm{~min}$ on each test day. Blood samples were collected at $60 \mathrm{~min}$ before copulation procedure, as well as 0 (immediately at the time of ejaculation or after $15 \mathrm{~min}$ if the ram did not respond to estrous female), 20 and $60 \mathrm{~min}$ after ejaculation. It must be noted that the males were isolated from females during the whole study period, and the only visual and olfactory contacts were allowed at the testing days. This experiment was replicated three times using the 10 rams in July and three times using the same rams in February. 


\subsection{Radioimmunoassay analysis}

All collected samples were assayed for testosterone and cortisol by the radioimmunoassay technique using validated testosterone (REF: RK-61M, LOT: 10416AB) and cortisol (REF: RK-240CT, LOT: 10425C) [ $\left.{ }^{125} \mathrm{I}\right]$ commercial RIA KITS (Institute of Isotopes, Budapest, Hungary). The intraassay coefficients of variations were 9.28 and $8.38 \%$, while the inter-assay coefficients of variations were 10.68 and $13.65 \%$ for testosterone and cortisol, respectively.

\subsection{Statistical analyses}

Statistical analyses were performed by using MINITAB 13.31 program (Minitab, Coventry, UK). Monthly variations of testosterone and cortisol levels were investigated by repeated one-way analysis of variance (ANOVA). Data regarding electro-ejaculation stimulation and copulation process were subjected to three-way ANOVA-3 using the general linear model procedure (GLM) including the season and the time as fixed factors and replication as a random factor (replication was done three times in each season). The analysis was followed by multiple pairwise comparisons using a post hoc (Tukey) test. The threshold of signification was set at $P<0.05$.

\section{Results}

The monthly changes in the concentration of testosterone and cortisol are illustrated in Fig. 1. Mean testosterone values from all rams were affected by month $(P<0.001)$. From March to June, a sustained testosterone rise was observed and the level was declined from June to October. The highest testosterone level was recorded in June, while the lowest was noted in December. In contrast to testosterone trend, cortisol showed a very low level in June and the highest one was observed in December with a significant month effect $(P<0.001)$.

The outlines of electro-ejaculation and copulation experiences are shown in Figs. 2 and 3. According to these findings, a sharp and significant $(P<0.001)$ increase in cortisol level occurred at 0 and 20 min post EE during both the breeding and non-breeding season. However, no difference was found between the two seasons for the same two end time points. A significant increase $(P<0.001)$ in cortisol level can also be seen in Fig. 3 following copulation process at 0 and $20 \mathrm{~min}$ point during the non-breeding season. Anyhow, no differences were noted between $-60,0,20$ and $60 \mathrm{~min}$ pre- and post-copulation points in the breeding season.

During the breeding season, the level of testosterone significantly differed at $60 \mathrm{~min}$ after EE stimulation than the one at $-60 \mathrm{~min}$. Nevertheless, no significant differences $(P>0.05)$ were noted between the four time points during the non-breeding season. The level of testosterone increased after copulation in the non-breeding season at 0 and 20 min

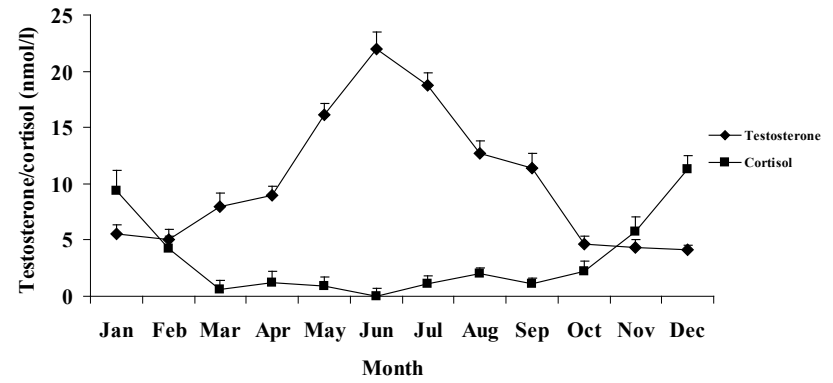

Figure 1. Variations in plasma testosterone and cortisol level in samples (mean \pm SEM) collected monthly in Syrian Awassi rams $(n=10)$.
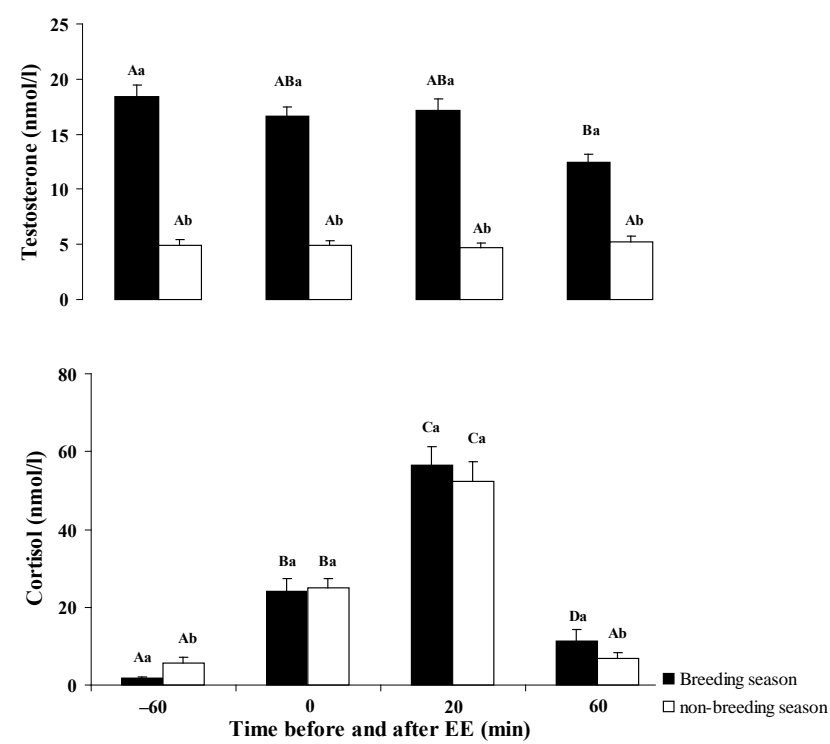

Figure 2. Mean ( \pm SEM) plasma testosterone and cortisol level prior to and following electro-ejaculation (EE) stimulation during breeding and non-breeding season. Values for each hormone with different letters within breeding and within non-breeding season (ABC) significantly differ $(P<0.05)$. Values for each hormone with different letters between breeding and non-breeding season $(\mathrm{ab}) \mathrm{sig}$ nificantly differ $(P<0.05)$.

points reaching a significant level only at $60 \mathrm{~min}(P<0.001)$. However, no differences were recorded in this hormone over the four time periods of this experiment during the breeding season $(P=0.146)$. Furthermore, clear significant differences $(P<0.001)$ were observed for each time point $(-60,0$, 20 and $60 \mathrm{~min}$ ) between the two seasons.

\section{Discussion}

The results reported in this study on Syrian Awassi rams showed a very clear and defined seasonal pattern. According to the climatological data, the increase in plasma testosterone levels was associated with the increase in photoperiod. 

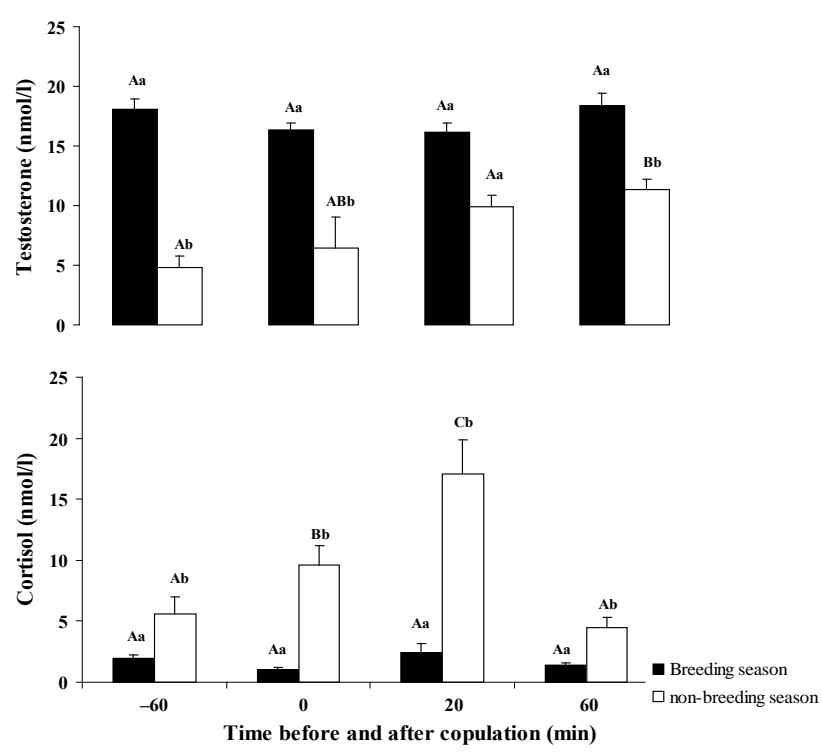

Figure 3. Mean ( \pm SEM) plasma testosterone and cortisol level prior to and following copulation process during breeding and nonbreeding season. Values for each hormone with different letters within breeding and within non-breeding season (ABC) significantly differ $(P<0.05)$. Values for each hormone with different letters between seasons $(\mathrm{ab})$ significantly differ $(P<0.05)$.

In a clear contrast to our results, a higher level of testosterone was found in rams during short days in comparison with long days (Gundogan, 2007). However, the influence of the photoperiod depends on sheep breeds and their location; those originating from temperate climates in mid and high latitudes are seasonal breeds, their breeding season being limited to autumn (Rhim et al., 1993); while, in tropical and subtropical climates, some breeds are almost or completely aseasonal. The latitudinal location of the current experiment $\left(33^{\circ} \mathrm{N}\right)$ could be partly responsible for shifting the breeding season in summer rather than in autumn. A pronounced increase in testosterone level in spring and summer seasons has been recorded in studies conducted by Olster and Foster (1988) and Taha et al. (2000). The previous authors suggested that in mature rams the stimulation of the hypothalamic-pituitary axis begins in spring when photoperiod increases. Anyhow, cyclic reproductive behaviour in rams could be influenced by environmental and hormonal factors other than photoperiod (e.g. nutrition, social interactions, temperature, and blood growth hormone) (Hamidi et al., 2012). In addition, a high percentage of Awassi females showed oestrus activity during June and July (Zarkawi, 1997) leading to a lag time in gonadal activity between males and females. This fact allows the synchronization of the first ovulations in the females with the maximum fertilization capacity of spermatozoa. Thus, the increase of testosterone secretion in Awassi rams which occurs in April and May followed by a clear peak in June may be necessary to succeed the breeding activity process of this breed between males and females later.

Cortisol and testosterone are both critical endocrinal variables that affect stress responses and sexual activity. However, the dearth of information concerning cortisol level in the ram throughout the year made it interesting to show the profile of the two hormones together. In the current study, cortisol level showed an inverse relation with testosterone and this was obvious in June and December. The high levels of cortisol in December and January may be partly related to the low temperature during these months of the year. Elevated circulating glucocorticoid levels as a response to cold stress were clearly documented in farm animals (Dantzer and Mormede, 1983). In contrast, the high temperature during summer did not affect cortisol level in Syrian Awassi rams, and this could be a result of an adaptation to harsh environmental conditions during this season. Although the seasonality pattern of cortisol in rams could be more related to the environmental factors, however, this matter needs additional research focusing on the endocrinal aspects.

The current study is the first to monitor the levels of cortisol and testosterone before and after electro-ejaculation and copulation in Awassi breed. The cortisol peak observed 20 min after EE represents a significant rise from the pre-EE levels in the breeding and non-breeding season. Similarly, criollo goats peaked $20 \mathrm{~min}$ post-EE stimulation but with a level of no more than $30 \mathrm{nmol} \mathrm{L}^{-1}$ at this time point (Ortiz de Montellano et al., 2007). Moreover, Damian and Ungerfeld (2011) reported that electro-ejaculated rams had an important stress response including changes in respiratory rate. Thus, welfare considerations should always be taken into account by the administration of sedative and/or analgesic medications after using such technique.

Testosterone levels in Awassi rams exposed to electrical stimulation treatments during the breeding season appeared to decline over time. A cause-effect relationship between adrenal hormones and testosterone levels following EE has been suggested for certain species such as cattle (Welsh and Johnson, 1981) and cats (Carter et al., 1984). On the other hand, during stressful events in mice, the blood level of testosterone may be reduced due to the deterioration of the blood flow in testicles (Kamiya et al., 2003). However, the reason for the stability of testosterone level in the four experimental times during the non-breeding season in this study may be attributed to the normal basal level of testosterone already found during this period.

It is well known that the presence of females and especially oestrus ones may change ram plasma testosterone (Stellflug, 2006). The rams of our study responded to oestrus ewes with an increase of 2.7 fold in testosterone levels only in the non-breeding season. Gonzalez et al. (1988a) noted a 3.5-fold increase in mean testosterone levels in rams after the introduction of oestrous females during the non-breeding season. The presence of oestrous females during the breeding season affected luteinizing hormone pulse frequency and in- 
creased testosterone levels in rams (Gonzalez et al., 1988b). Anyhow, sexual experience of Awassi rams and the period of cohabitation may modify the testosterone response to copulation process.

\section{Conclusions}

Taken together, the findings of the present investigation suggest that, under local Syrian conditions, Awassi rams have a distinct testosterone and cortisol seasonality pattern. Testosterone and cortisol have obvious inverse relation in June and December. Cortisol levels indicate an acute stress response to EE treatment, especially at 0 and 20 min with no differences between response according to breeding and non-breeding season. In Syrian Awassi sheep, females have an effect on the testosterone of rams and cortisol concentrations only during the non-breeding season.

Acknowledgements. The authors would like to thank the Director General and the Head of the Department of Agriculture, Atomic Energy Commission of Syria for their support while conducting the experiments.

Edited by: S. Maak

Reviewed by: two anonymous referees

\section{References}

Avdi, M., Driancourt, M. A., and Chemineau, P.: Variations saisonnières du comportement d'oestrus et de l'activité ovulatoire chez les brebis Chios et Serres en Grèce, Reprod. Nutr. Dev., 33, 1524, 1993.

Carter, K. K., Chakraborty, P. K., Bush, M., and Wildt, D. E.: Effects of electroe-jaculation and ketamine-HCL on serum cortisol, progesterone, and testosterone in the male cat, J. Androl., 5, 431437, 1984

Damian, J. P. and Ungerfeld, R.: The stress response of frequently electroejaculated rams to electroejaculation: Hormonal, physiological, biochemical, haematological and behavioural parameters, Reprod. Dom. Anim., 46, 646-650, 2011.

Dantzer, R. and Mormede, P.: Stress in farm animals: a need for reevaluation, J. Anim. Sci., 57, 6-17, 1983.

Fox, C. A., Ismail, A. A. A., Love, D. N., Kirkham, K. E., and Loraine, J. A.: Studies on the relationship between plasma testosterone levels and human sexual activity, J. Endocrinol., 52, 5158, 1972.

Galal, S., Gursoy, O., and Shaat, I.: Awassi sheep as a genetic resource and efforts for their genetic improvement - A review, Small. Rumin. Res., 79, 99-108, 2008.

Garcia-Alvarez, O., Maroto-Morales, A., Martinez-Pastor, F., Garde, J. J., Ramon, M., Fernandez-Santos, M. R., Esteso, M. C., Perez-Guzman, M. D., and Soler, A. J.: Sperm characteristics and in vitro fertilization ability of thawed spermatozoa from Black Manchega ram: Electroejaculation and postmortem collection, Theriogenology, 27, 160-168, 2009.
Gonzalez, R., Orgeur, P., and Signoret, J. P.: Luteinizing hormone, testosterone and cortisol responses in rams upon presentation of estrous females in the nonbreeding season, Theriogenology, 30, 1075-1086, 1988a.

Gonzalez, R., Poindron, P., and Signoret, J. P.: Temporal variation in $\mathrm{LH}$ and testosterone responses of rams after the introduction of oestrous females during the breeding season, J. Reprod. Fertil., 83, 201-208, 1988b.

Gonzalez, R., Orgeur, P., Poindron, P., and Signoret, J. P.: Female effect in sheep. I. The effects of sexual receptivity of females and the sexual experience of rams, Reprod. Nut. Dev., 31, 97-102, 1991.

Gundogan, M.: Seasonal variation in serum testosterone, $\mathrm{T}_{3}$ and andrological parameters of two Turkish sheep breeds, Small. Rumin. Res., 67, 312-316, 2007.

Hamidi, A., Mamoei, M., Mirzadeh, K., Tabatabaei, S., and Roshanfekr, H. A.: Correlation between blood growth hormone profile and reproduction performance in Arabic rams, Comp. Clinc. Path., 21, 819-823, 2012.

Iniguez, L. and Hilali, M.: Evaluation of Awassi genotypes for improved milk production in Syria, Livest. Sci., 120, 232-239, 2009.

Kafi, M., Safdarian, M. and Hashemi, M.: Seasonal variation in semen characteristics, scrotal circumference and libido of Persian Karakul rams, Small. Rumin. Res., 53, 133-139, 2004.

Kamiya, H., Sasaki, S., Ikeuchi, T., Umemoto, Y., Tatsura, H., Hayashi, Y., Kaneko, S., and Kohri, K.: Effect of simulated microgravity on testosterone and sperm motility in mice, J. Androl., 24, 885-890, 2003.

Kannan, G., Terril, T. H., Kouakou, B., Gelaye, S., and Amoah, E. A.: Simulated preslaughter holding and isolation effects on stress responses and live weight shrinkage in meat goats, J. Anim. Sci., 80, 1771-1780, 2002.

Katongole, C. B., Naftolin, F., and Short, R. V.: Relationship between blood levels of luteinizing hormone and testosterone in bulls and the effects of sexual stimulation, J. Endocr., 50, 457466, 1971.

Kridli, R. T., Abdullah, A. Y., Obeidat, B. S., Qudsieh, R. I., Titi, H. H., and Awawdeh, M. S.: Seasonal variation in sexual performance of Awassi rams, Anim. Reprod., 4, 38-41, 2007.

Langford, G. A., Sanford, L. M., Marcus, G. J., and Shrestha, J. N. B.: Seasonal cyclic pituitary and testicular activities in rams, Small. Rumin. Res., 33, 43-53, 1999.

Mosure, W. L., Meyer, R. A., Gudmondson, J., and Barth, A. D.: Evaluation of possible methods to reduce pain associated with electoejaculation in bull, Can. Vet. J., 39, 504-506, 1998.

Olster, D. H. and Foster, D. L.: Control of gonadotrophin secretion during the pubertal and seasonal transitions in male sheep, J. Reprod. Fertil., 82, 179-191, 1988.

Ortiz-de-Montellano, M., Galindo-Maldonado, F., Cavazos-Arizpe, E. O., Aguayo-Arceo, A. M., Torres-Acosta, J. F. J., and Orihuela, A.: Effect of electro-ejaculation on the serum cortisol response of Criollo goats (Capra hirus), Small. Rumin. Res., 69, 228-231, 2007.

Palmer, C. W.: Welfare aspects of theriogenology: Investigating alternatives to electroejaculation of bulls, Theriogenology, 64, 469-479, 2005.

Purvis, K., Illius, A. W., and Haynes, N. B.: Plasma testosterone concentrations in the ram, J. Endocrinol., 61, 241-253, 1974. 
Purvis, K. and Haynes, N. B.: Short-term effects of copulation, human chorionic gonadotrophin injection and non tactile association with a female on testosterone levels in the male rat, J. Endocrinol., 60, 429-439, 1974.

Rhim, T. J., Kuehl, D., and Jackson, G. I.: Seasonal changes in the relationships between secretion of gonadotropin-releasing hormone, luteinizing hormone and testosterone in the ram, Biol. Reprod., 48, 197-204, 1993.

Rosa, H. J. D. and Bryant, M. J.: Seasonality of reproduction in sheep, Small. Rumin. Res., 48, 155-171, 2003.

Stellflug, J. N.: Comparison of cortisol, luteinizing hormone, and testosterone responses to a defined stressor in sexually inactive rams and sexually active female-oriented and male-oriented rams, J. Anim. Sci., 84, 1520-1525, 2006.
Taha, T. A., Abdel-Gawad, E. I., and Ayoub, M. A.: Monthly variations in some reproductive parameters of Barki and Awassi rams throughout 1 year under subtropical conditions 1 - Semen characteristics and hormonal levels, J. Anim. Sci., 71, 317-324, 2000.

Welsh, T. H. and Johnson, B. H.: Stress-induced alterations in secretion of corticosteroids, progesterone, luteinizing hormone, and testosterone in bulls, Endocrinology, 109, 185-190, 1981.

Wulster-Radcliffe, M. C., Williams, M. A., Stellflug, J. N., and Lewis, G. S.: Technical note: artificial vagina vs a vaginal collection vial for collection semen from rams, J. Anim. Sci., 79, 2964-2967, 2001.

Zarkawi, M.: Monitoring the reproductive performance in Awassi Ewes using progesterone radioimmunoassay, Small. Rumin. Res., 26, 291-294, 1997. 